Note

\title{
A Simple Turbidimetric Assay Using Chitin Nanofibers as the Substrate for Determinination of Chitinase Activity
}

\author{
(Received August 4, 2014; Accepted October 7, 2014) \\ (J-STAGE Advance Published Date: October 20, 2014) \\ Tomoyo Nishihira, ${ }^{1}$ Asami Miyano, ${ }^{1}$ Takayuki Ohnuma, ${ }^{1, *}$ Takeshi Gotoh, ${ }^{2}$ \\ Saori Takahashi, ${ }^{3}$ Kazue Narihiro, ${ }^{4}$ Kazuhiko Yamashita ${ }^{4}$ and Tamo Fukamizo ${ }^{1}$ \\ ${ }^{1}$ Department of Advanced Bioscience, Kinki University (3327-204 Nakamachi, Nara 631-8505, Japan) \\ ${ }^{2}$ Department of Engineering and Applied Chemistry, Graduate School of Engineering and Resource Science, Akita University \\ (1-1 Tegata gakuen-machi, Akita 010-8502, Japan) \\ ${ }^{3}$ Akita Research Institute of Food and Brewing \\ (4-26 Sanuki, Araya-machi, Akita 010-1623, Japan) \\ ${ }^{4}$ Yaegaki Bio-industry, Inc. (681 Mukudani, Hayashida-cho, Himeji 678-4298, Japan)
}

\begin{abstract}
A simple turbidimetric assay using chitin nanofiber as the substrate was employed to measure chitinase activity. The higher dispersive properties of chitin nanofibers enabled the degradation of chitin to be monitored turbidimetrically. When non-processive chitinases, a family GH18 chitinase from the tobacco plant and a GH19 chitinase from rye seeds, were added to the $\beta$-chitin nanofiber suspension, no significant changes were observed in the turbidity of the suspension, however, the amounts of reducing sugars produced were significantly high and small amounts of GlcNAc and (GlcNAc)2 were detected by HPLC in the reaction mixture. However, the addition of a processive family GH18 chitinase, Serratia marcescence chitinase B or chitinase from Autographa californica multiple nucleopolyhedrovirus, resulted in a significant decrease in the turbidity of the chitin nanofiber suspension, and produced larger amounts of reducing sugars including GlcNAc and (GlcNAc)2. The rate of decreases in turbidity was clearly dependent upon the enzyme concentration. We concluded that the turbidimetric assay using $\beta$-chitin nanofibers as the substrate was useful for measuring the activities of processive chitinases.
\end{abstract}

Key words: chitinase, $\beta$-chitin, nanofiber, turbidimetry, processive mechanism

Chitin is a $\beta$-1,4-linked polysaccharide of $N$-acetylglucosamine, $(\mathrm{GlcNAc})_{n}$ ( $n$, degree of polymerization or chain length) and the second most abundant biopolymer after cellulose. This polysaccharide mainly occurs in crustacean shells, insect cuticles and peritrophic membranes, fungal cell walls, and on the outer surfaces of protozoan and metazoan parasites. ${ }^{1)}$ Although at least 10 gigatons $\left(1 \times 10^{13} \mathrm{~kg}\right)$ of chitin are biosynthesized per year, the vast majority is not fully utilized and ultimately discarded. The industrial production of chitin is now mainly conducted from crab and shrimp shells, and the chitin produced is further processed into various materials used in medical treatments, food additives, and fertilization. ${ }^{2}$ A simple method for the preparation of chitin nanofibers, which are generally defined as fibers with a diameter of less than $100 \mathrm{~nm}$ and an aspect ratio of more than 100 , has recently been developed. ${ }^{3)}$

Chitinases (EC 3.2.1.14) are chitin-degrading enzymes that are capable of hydrolyzing the $\beta$-1,4-linkages of chitin. $\left.{ }^{4}\right)$ These enzymes have been widely detected in organisms ranging from bacteria to humans, and act as defense proteins against various biotic and abiotic stresses. ${ }^{5)}$ Various assay

* Corresponding author (Tel. +81-742-43-7297, Fax. +81-742-43-8976, E-mail: ohnumat@nara.kindai.ac.jp).

Abbreviations: GlcNAc, 2-acetamido-2-deoxy-D-glucopyranose; (GlcNAc) $n, \beta-1,4-$ linked oligosaccharide of GlcNAc with a polymerization degree of $n$. methods have been employed to determine chitinase activity. The monitoring method most commonly used is based on increases in the amount of reducing sugars from the polysaccharide substrates, such as colloidal chitin and glycol chitin. ${ }^{6}$ This method requires a laborious photometric procedure to determine the reducing ends produced by hydrolysis. Spectroscopic changes have also been employed to monitor enzymatic hydrolysis using synthetic oligosaccharide substrates. In this case, a chromophoric group, such as $p$-nitrophenyl or 4-methylumbelliferyl group, has to be introduced into GlcNAc oligosaccharides by synthetic methods to obtain the chromophoric substrates. ${ }^{7,8)}$ However, the synthesis of such substrates is generally time-consuming and expensive. Furthermore, the chromophoric groups attached to native substrates can affect the kinetic behavior of enzymes, producing an artifact in the results obtained. ${ }^{9)}$ It is highly desirable to develop a more convenient assay system for determination of chitinase activity using natural chitin substrates. In the present study, we attempted to determine chitinase activity using a turbidimetric assay with chitin nanofibers as the substrate.

$\beta$-Chitin was prepared from the squid pen, and powdered with a pulverizer to under $300 \mu \mathrm{m}$. The fine $\beta$-chitin powder was dispersed in water at $2 \%(w t)$, and the suspension was passed through the Star Burst system (Sugino Machine Co., Ltd., Uozu, Japan) using our original ultrahigh-pressure 
water jet technology. The $\beta$-chitin nanofibers obtained were found to be regular fibers that were fully transparent and highly viscous in suspension. $\alpha$-Chitin nanofibers were prepared in a similar manner to that for $\beta$-chitin nanofibers except, that $\alpha$-chitin was prepared from crab shells. A family GH18 chitinase B from Serratia marcescence (SmChiB), ${ }^{10)}$ GH18 (class V) chitinase from Nicotiana tabacum (NtChiV), ${ }^{11)}$ and GH18 chitinase from Autographa californica multiple nucleopolyhedrovirus (AcMNPV) ${ }^{12}$ ) were expressed and purified using methods discribed previously. A family GH19 chitinase from rye seeds (RSC-c) was also produced according to the method of Ohnuma et al. ${ }^{13)}$ The specific activities of the individual chitinases were determined based on increases in the amount of reducing sugars from the soluble substrate, glycol chitin by the method of Imoto and Yagishita. ${ }^{14)}$ Because of the higher dispersive properties of the chitin nanofiber suspension, we employed a turbidimetric assay to monitor the hydrolysis of chitin nanofibers as the substrate. Chitin nanofibers suspended in distilled water (2\%) were mixed with $50 \mathrm{mM}$ sodium acetate buffer $\mathrm{pH} 5.0$ to obtain an optical density of $1.0^{-1.2}$ at $540 \mathrm{~nm}$. Each chitinase solution $(20 \mu \mathrm{L})$ dialyzed against $20 \mathrm{mM}$ sodium acetate buffer $\mathrm{pH} 5.0$ was added to $1 \mathrm{~mL}$ of the chitin nanofiber suspension, and the mixture was then incubated at $37^{\circ} \mathrm{C}$ with shaking at $100 \mathrm{rpm}$. The final enzyme concentrations were in $0.2-1.0 \mu \mathrm{M}$. After being incubated for a given reaction time, optical density at $540 \mathrm{~nm}$ was determined, and chitinase activity was evaluated based on decreases in turbidity. The reducing sugars in the reaction mixture were also determined in a similar manner to that for specific activity toward glycol chitin for comparative purpose. The major enzymatic products, the chitin monomers and dimers, GlcNAc and (GlcNAc)2, in the supernatant fraction of the reaction mixture were also determined by HPLC using a column of TSKgel Amide-80 (4.6 × $250 \mathrm{~mm}$, Tosoh Co., Tokyo, Japan) with the isocratic elution of $70 \%$ acetonitrile. ${ }^{11}$ ) The flow rate was $0.8 \mathrm{~mL} / \mathrm{min}$.

Before testing with chitin nanofibers as the substrate, we determined the specific activities of SmChiB, AcMNPV, $\mathrm{NtChiV}$ and RSC-c toward the soluble substrate, glycol chitin. The results are shown in Table 1. SmChiB was found to be the most active toward the soluble substrate. The activities of the other enzymes were lower than that of SmChiB (less than $50 \%$ ). We initially tested the $\beta$-chitin nanofiber as the substrate for the non-processive chitinases, $\mathrm{NtChiV}$ and RSC-c. As shown in Fig. 1, contrary to our expectations, the turbidity of the substrate suspension actually increased. Since the turbidity of the control experiments (without enzyme) also increased to the same extent, these increments were not attributed to the addition of enzyme proteins, but may have been due to the spontaneous aggregation of the chitin nanofibers themselves. NtChiV and RSC-c were more or less active toward the glycol chitin substrate (Table 1), and increased the amounts of reducing sugars in the chitin nanofiber suspension. In fact, the amount of reducing sugars released by $0.2 \mu \mathrm{M}$ RSC-c from $\beta$-chitin nanofiber after $3 \mathrm{~h}$ incubation is $35 \mu \mathrm{g} / \mathrm{mL}$ (data not shown). Nevertheless, the hydrolytic actions of the non-processive enzymes did not reduce the turbidity. The endo-splitting actions of the non-processive enzymes toward the chitin nanofibers were unlikely to have caused a marked reduction in the average
Table 1. Specific activities of NtChiV, RSC-c, SmChiB and AcMNPV toward soluble substrate, glycol chitin.

\begin{tabular}{lcc}
\hline Enzyme & $\begin{array}{c}\text { Specific activity } \\
(\mathrm{U} / \mathrm{mg})\end{array}$ & $\begin{array}{c}\text { Relative activity } \\
(\%)\end{array}$ \\
\hline NtChiV & 0.61 & 38 \\
RSC-c & 0.28 & 18 \\
SmChiB & 1.59 & 100 \\
AcMNPV & 0.34 & 21 \\
\hline
\end{tabular}

One unit of activity was defined as the enzyme activity that produced $1 \mu \mathrm{mol}$ of GlcNAc per minute at $37^{\circ} \mathrm{C}$. The enzyme activity is the average of duplicate assays.

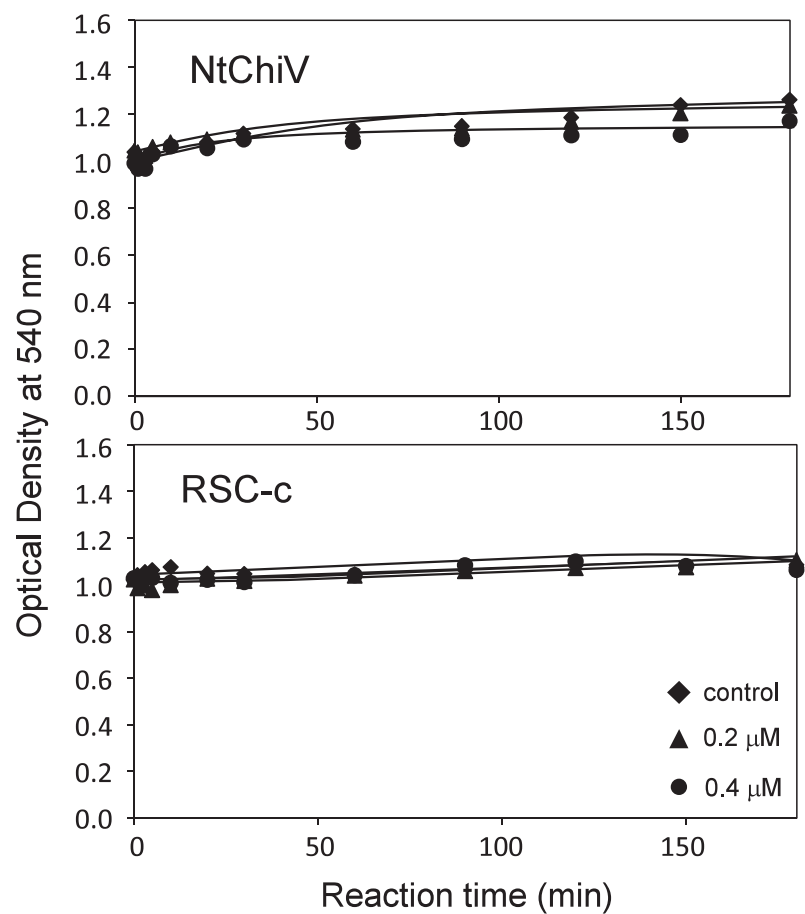

Fig. 1. Turbidimetric determination of the enzymatic hydrolysis of $\beta$-chitin nanofibers using the non-processive chitinases, $\mathrm{NtChiV}$ (GH18) and RSC-c (GH19).

The enzymatic reaction was conducted in $0.1 \mathrm{M}$ sodium phosphate buffer $\mathrm{pH}$ 7.0. A suspension of $\beta$-chitin nanofibers $(2 \%)$ was mixed with the same buffer to obtain 1.0 of OD $540 \mathrm{~nm}$. Twenty micro liters of the enzyme solution was added to the suspension $(1.0 \mathrm{~mL})$, which was then incubated at $37^{\circ} \mathrm{C}$ with constant shaking at $100 \mathrm{rpm}$. In this figure and in all subsequent figures depicting measurements of chitinase activity, each point is the average of duplicate determinations (Results of the duplicate determinations were always within $5 \%$ of each other).

chain lengths of (GlcNAc) $n$, which causes the decrease in turbidity.

On the other hand, when two processive enzymes, SmChiB and AcMNPV, were added to the chitin nanofiber suspension, the turbidity of the suspension decreased with as the reaction time progressed, as shown in Fig. 2. The turbidity decrease caused by $0.2 \mu \mathrm{M}$ SmChiB was approximately $0.5 \mathrm{OD}$ units after $3 \mathrm{~h}$ incubation, while $0.4 \mu \mathrm{M}$ and $1.0 \mu \mathrm{M}$ $\mathrm{SmChiB}$ resulted in turbidity decreases of approximately 0.6 and 0.8 OD units after $3 \mathrm{~h}$, respectively (Fig. 2 upper panel). The dependency of turbidity decreases on the enzyme concentration suggested that turbidity decreases were derived from the enzymatic hydrolysis of the chitin nanofibers. Similar results were obtained for AcMNPV, although the activity of AcMNPV was lower than that of SmChiB. A turbidity decrease of 0.3 OD units was observed after $3 \mathrm{~h}$ incubation 


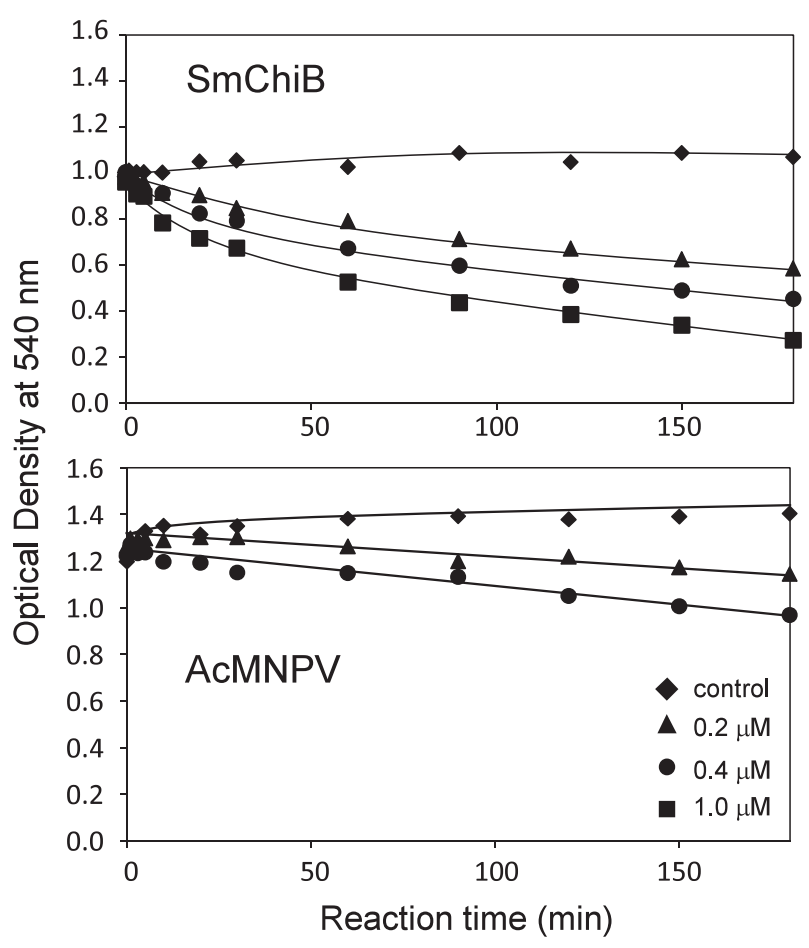

Fig. 2. Turbidimetric determination of the enzymatic hydrolysis of $\beta$-chitin nanofibers using the processive chitinases, $\mathrm{SmChiB}$ (GH18) and AcMNPV (GH18).

The enzymatic reaction conditions were the same as for Fig. 1.

with $0.2 \mu \mathrm{M}$ AcMVPV, and was 0.4 OD units with $0.4 \mu \mathrm{M}$ AcMNPV (Fig. 2 lower panel). The amount of reducing sugars released by $0.2 \mu \mathrm{M}$ AcMNPV from $\beta$-chitin nanofiber after $3 \mathrm{~h}$ incubation is $261 \mu \mathrm{g} / \mathrm{ml}$ (data not shown). The turbidity decrease was again dependent on the enzyme concentration. Thus, we concluded that hydrolytic reactions catalyzed by processive chitinases can be monitored by turbidimetry using $\beta$-chitin nanofibers as the substrate.

The reaction mixture was centrifuged and the supernatant was applied onto a column of TSKgel Amide- 80 in order to analyze the products in the reaction mixture. Based on the retention time, the major products were identified as GlcNAc and (GlcNAc)2. Figure 3 shows the amounts of GlcNAc and (GlcNAc)2 produced by the $3 \mathrm{~h}$ and $24 \mathrm{~h}$ incubations with the individual enzymes. As suggested from the turbidimetric data (Figs.1 and 2), the amounts of GlcNAc and (GlcNAc)2 produced by the processive enzymes SmChiB and AcMNPV were markedly higher than those produced by the non-processive enzymes, RSC-c and NtChiV. Although the enzymatic activity of $\mathrm{SmChiB}$ evaluated from the turbidimetry assays was markedly higher than that of AcMNPV (Fig. 2), ${ }^{12)}$ the amounts of GlcNAc and (GlcNAc)2 produced by SmChiB were similar to those produced by AcMNPV. This may have been due to the difference in the number of cuts for each enzyme substrate association, $N$ cuts, which represents the degree of processivity. ${ }^{15)}$ The values of $N$ cuts for Serratia marcescens chitinase $\mathrm{A}$ (SmChiA) and $\mathrm{SmChiB}$ were reported to be 9.1 and 3.4. The degree of processivity of SmChiB was lower than that of SmChiA. Since the structure and function of AcMNPV was more related to those of SmChiA, ${ }^{12)}$ the degree of processivity may have been higher than that of SmChiB.

We also examined $\alpha$-chitin nanofibers derived from crab

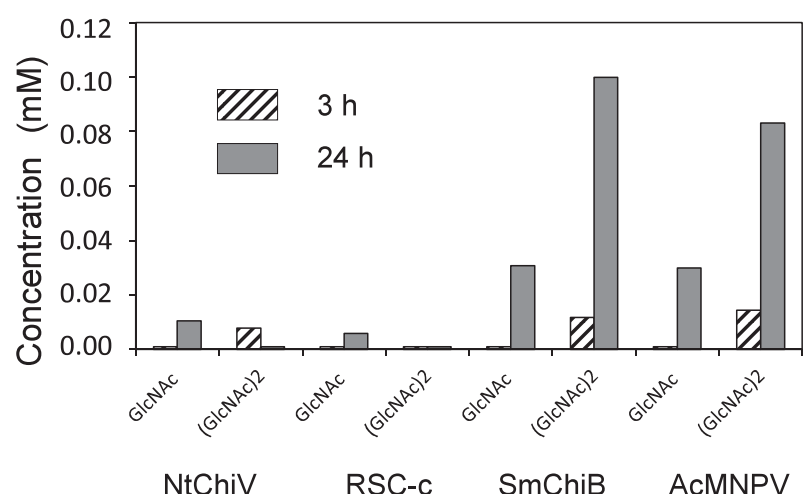

Fig. 3. The amounts of GlcNAc and (GlcNAc)2 produced from $\beta$-chitin nanofibers by the individual enzymes.

The reaction conditions were the same as those in Figs. 1 and 2. The supernatant fraction was applied to HPLC.

shells as the substrate for the turbidimetric chitinase assay. No significant decrease was observed in turbidity for $\mathrm{SmChiB}$ (data not shown). This was attributed to the lower enzymatic activity of the enzyme toward $\alpha$-chitin. ${ }^{16)}$ Therefore, the turbidimetric chitinase assay was concluded to be more suitable for the reaction system of processive chitinases and $\beta$-chitin nanofibers.

In conclusion, $\beta$-chitin nanofibers were found to be useful as the substrate for the turbidimetric chitinase assay, which did not require any chemical conversion of the substrate or product. The activity data obtained by this method (Fig. 2) were almost consistent with data based on increases in the amounts of the reducing sugars from the substrate, solid $\beta$-chitin, ${ }^{12)}$ and with the activity data toward the soluble substrate glycol chitin (Table 1). However, activity data could not be obtained for non-processive chitinases. Thus, this assay system could be used to determine if a chitinase is processive or non-processive.

\section{ACKNOWLEDGMENTS}

This work was supported by "Strategic Project to Support the Formation of Research Bases at Private Universities: Matching Fund Subsidy from MEXT (Ministry of Education, Culture, Sports, Science and Technology), 2011-2015 (S1101035).

\section{REFERENCES}

1 ) K.D. Spindler, M. Spindler-Barth and M. Londershausen: Chitin metabolism: a target for drugs against parasites. Parasitol. Res., 76, 283-288 (1990).

2 ) F. Khoushab and M. Yamabhai: Chitin research revisited. Mar. Drugs, 8, 1988-2012 (2010).

3 ) S. Ifuku and H. Saimoto: Chitin nanofibers: preparations, modifications, and applications. Nanoscale, 4, 3308-3318 (2012).

4 ) T. Fukamizo: Chitinolytic enzymes: catalysis, substrate binding, and their application. Curr. Protein Pept. Sci., 1, 105-124 (2000).

5 ) Y. Arakane, T. Taira, T. Ohnuma and T. Fukamizo: Chitin-related enzymes in agro-biosciences. Curr. Drug Targets, 13, 442-470 (2012).

6 ) H. Yamada and T. Imoto: A convenient synthesis of glycolchitin, a substrate of lysozyme. Carbohydr. Res., 92, 160-162 (1981).

7 ) F. Nanjo, K. Sakai and T. Usui: $p$-Nitrophenyl penta- $N$-acetyl- $\beta$ chitopentaoside as a novel synthetic substrate for the colorimetric assay of lysozyme. J. Biochem., 104, 255-258 (1988).

8 ) Y. Yang, S. Kuramitsu and K. Hamaguchi: Hydrolysis of 4-methylumbelliferyl $N$-acetyl-chitooligosaccharides catalyzed by human lysozyme. J. Biochem., 89, 1357-1366 (1981).

9 ) I.M. Krokeide, B. Synstad, S. Gåseidnes, S.J. Horn, V.G. Eijsink 
and M. Sørlie: Natural substrate assay for chitinases using highperformance liquid chromatography: a comparison with existing assays. Anal. Biochem., 363, 128-134 (2007).

10) Y. Honda, M. Kitaoka, K. Tokuyasu, C. Sasaki, T. Fukamizo and K. Hayashi: Kinetic studies on the hydrolysis of $N$-acetylated and $\mathrm{N}$-deacetylated derivatives of 4-methylumbelliferyl chitobioside by the family 18 chitinases ChiA and ChiB from Serratia marcescens. J. Biochem., 133, 253-258 (2003).

11) T. Ohnuma, T. Numata, T. Osawa, M. Mizuhara, K.M. Vårum and T. Fukamizo: Crystal structure and mode of action of a class V chitinase from Nicotiana tabacum. Plant Mol. Biol., 75, 291-304 (2011).

12) T. Fukamizo, H. Sato, M. Mizuhara, T. Ohnuma, T. Gotoh, K. Hiwatashi and S. Takahashi: Chitinase from Autographa californica multiple nucleopolyhedrovirus: rapid purification from Sf-9 medium and mode of action. Biosci. Biotechnol. Biochem., 75,
1763-1769 (2011).

13) T. Ohnuma, M. Yagi, T. Yamagami, T. Taira, Y. Aso and M. Ishi guro: Molecular cloning, functional expression, and mutagenesis of cDNA encoding rye (Secale cereale) seed chitinase-c. Biosci. Biotechnol. Biochem., 66, 277-284 (2002).

14) T. Imoto and K. Yagishita: A Simple activity measurement of lysozyme. Agric. Biol. Chem., 35, 1154-1156 (1971).

15) P. Sikorski, A. Sørbotten, S.J. Horn, V.G.H. Eijsink and K.M Vårum: Serratia marcescens chitinases with tunnel-shaped substrate-binding grooves show endo activity and different degrees of processivity during enzymatic hydrolysis of chitosan. Biochemistry, 45, 9566-9574 (2006).

16) S.J. Horn, M. Sørlie, G. Vaaje-Kolstad, A.L. Norberg, B. Synstad, K.M. Vårum and V.G. Eijsink: Comparative studies of chitinases A, B, and C from Serratia marcescens. Biocatal. Biotransform., 24, 39-53 (2006). 